\title{
NS-398 promotes pancreatic cancer cell invasion by CD147 and MMP-2 via the activation of P38
}

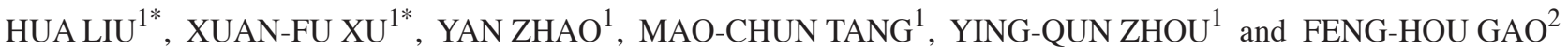 \\ ${ }^{1}$ Department of Gastroenterology, The Tenth Hospital Affiliated to Tongji University, Shanghai 200072; ${ }^{2}$ Institute of Oncology, \\ Shanghai 9th People's Hospital, Shanghai Jiao Tong University School of Medicine, Shanghai 200011, P.R. China
}

Received January 19, 2015; Accepted October 29, 2015

DOI: $10.3892 / \mathrm{mmr} .2016 .4783$

\begin{abstract}
The overexpression or abnormal activation of cyclo-oxygenase-2 (COX-2) has been reported in pancreatic cancer cells. NS-398, a selective inhibitor of COX-2, is unable to inhibit pancreatic cancer cell proliferation, as determined by a Cell Counting Kit 8 assay. However, it does increase cancer cell invasiveness, and therefore the invasiveness of the PANC-1 cells was determined, along with the activation of P38, which was assessed by western blotting. In the present study, to evaluate the mechanisms underlying the action of NS-398 in pancreatic cancer cells, PANC-1 cells were treated with NS-398, and the invasion signaling pathways of cluster of differentiation (CD)147-matrix metalloproteinase (MMP)-2 and mitogen-activated protein kinases were evaluated. The results showed that NS-398-induced the expression of CD147 and MMP-2 via the activation of P38, which was involved in antiproliferative activity and induced pancreatic cancer cell invasiveness. The PANC-1 cells were also co-treated with CD147 small interfering (si)RNA and NS-398, and it was found that the NS-398-induced activation of P38 was not inhibited by CD147 siRNA, however, the expression of MMP-2 was inhibited. CD147 siRNA inhibited the invasiveness of the pancreatic cancer cells induced by NS-398, but also restored NS-398-induced antiproliferative activity. These data indicated that P38 in the pancreatic cancer cells was non-specifically activated by NS-398. This activation induced the expression
\end{abstract}

Correspondence to: Dr Hua Liu, Department of Gastroenterology, The Tenth Hospital Affiliated to Tongji University, 301 Yanchang Road, Shanghai 200072, P.R. China

E-mail: luhua_lh@163.com

Dr Feng-Hou Gao, Institute of Oncology, Shanghai 9th People's Hospital, Shanghai Jiao Tong University School of Medicine, 639 Zhi Zao Ju Road, Shanghai 200011, P.R. China.

E-mail: fenghougao@163.com

*Contributed equally

Key words: NS-398, matrix metalloproteinase-2, pancreatic cancer cell, cluster of differentiation 147, invasion of CD147-MMP-2, opposed the antiproliferative activity of NS-398 and increased the invasiveness of the PANC-1 cells.

\section{Introduction}

Pancreatic cancer often has a poor prognosis, with the median survival rates for metastatic disease, which collectively accounts for $>80 \%$ of the affected individuals, is $\sim 6$ months (1). This process of metastasis is not random (2). A cascade of complex interactions between the cancer cell and its surroundings results in a metastatic cascade (3), in which the tumor cells initially break signaling contact with neighboring cells, degrade and penetrate the basement membrane and then invade the interstitial stroma in order to reach the blood/lymph vessels $(4,5)$. Therefore, there is an urgent requirement to develop molecular diagnostic biomarkers and targets to detect pancreatic cancer at an earlier stage, which may assist in improving the treatment success and survival rates of patients with pancreatic cancer.

Cyclooxygenase (COX), also known as prostaglandin endoperoxidase or prostaglandin $\mathrm{G} / \mathrm{H}$ synthase, is a rate-limiting enzyme involved in the conversion of arachidonic acid to prostaglandins (6). Two forms of COX, COX-1 and COX-2, have been identified. COX-1 is constitutively expressed in several tissues and is responsible for various physiological functions, whereas COX-2 is an inducible enzyme, originally found to be induced by growth factors and other stimuli (7). Previous studies have demonstrated the relevance of COX-2 in human cancer, including colorectal cancer, cholangiocarcinoma, liver cancer, esophageal carcinoma, gastric cancer and pancreatic cancer (8-13). Determinants of cell invasion, including cell motility, adhesion to the extracellular matrix and the gelatinolytic activity of metalloproteinase, are also modulated in COX-2-positive pancreatic cancer cells (14). Therefore, COX-2-specific inhibitors may provide a useful anti-invasive therapeutic option in the treatment of pancreatic cancer.

NS-398 is a selective inhibitor of COX-2 (15). Previous studies have indicated that NS-398 resists carcinogenesis through anti-angiogenic and pro-apoptotic effects (16). Few studies have focused on the anti-invasive and antimetastatic effects of NS-398 in cancer, and the effects of NS-398 on pancreatic cancer cell invasiveness, and its exact underlying mechanisms remain to be fully elucidated. 
In the present study, the proliferative and invasive effects of NS-398 on pancreatic cancer cells were evaluated. The corresponding molecular mechanisms underpinning the observed effects have also been analyzed in depth. The present study has provided an experimental basis for the joint application of NS-398 and P38 inhibitors in pancreatic cancer cells.

\section{Materials and methods}

Reagents. NS-398 was obtained from Sigma-Aldrich (St. Louis, MO, USA). The NS-398 was dissolved in dimethyl sulfoxide (DMSO; Sigma-Aldrich, St. Louis, MO, USA) at a stock concentration of $100 \mathrm{mM}$, and stored at $-20^{\circ} \mathrm{C}$. SB-203580 was obtained from Cell Signaling Technology, Inc. (Danvers, MA, USA) and dissolved in DMSO at a stock concentration of $10 \mathrm{mM}$. All stock solutions were wrapped in foil and maintained at $4^{\circ} \mathrm{C}$ or $-20^{\circ} \mathrm{C}$.

Cell culture. The PANC-1 pancreatic cancer cell line was purchased from the Shanghai Institutes for Biological Sciences (Shanghai, China). The cells were maintained in humidified room air containing $5 \% \mathrm{CO}_{2}$ at $37^{\circ} \mathrm{C}$, and were cultured in Dulbecco's modified Eagle's medium (DMEM; Gibco; Thermo Fisher Scientific, Inc., Waltham, MA, USA) supplemented with $10 \%$ fetal bovine serum and $1 \%$ penicillin-streptomycin (Gibco; Thermo Fisher Scientific, Inc.). Cells in the logarithmic phase of growth were used in all subsequent experiments.

Cell Counting Kit-8 assay. The pancreatic cancer cells were seeded at a concentration of $5 \times 10^{3}$ cells/200 $\mu \mathrm{l} /$ well in 96 -well culture plates for the cell proliferation assay. Briefly, the cultured wells were treated with $20 \mu \mathrm{l} /$ well of Cell Counting Kit-8 reagent (Dojindo Molecular Technologies, Inc., Kumamoto, Japan) during the final $2 \mathrm{~h}$ of a $24 \mathrm{~h}$ incubation period at $37^{\circ} \mathrm{C}$, and the optical density (OD) of each well was measured at $450 \mathrm{~nm}$ using a Model 680 Bio-Rad microplate reader (Bio-Rad Laboratories, Inc., Hercules, CA, USA). The results of cell proliferation measurement were expressed as the absorbance at OD450.

Enzyme-linked immunosorbent assay (ELISA). The pancreatic cancer cells $\left(3 \times 10^{5}\right)$ were seeded in each well of a 6-well plate (Corning Incorporated, Corning, NY, USA) with $1 \mathrm{ml}$ complete medium. The cells were starved in serum-free DMEM for $24 \mathrm{~h}$ at $37^{\circ} \mathrm{C}$ prior to stimulation. Following stimulation with NS 398 for the durations indicated subsequently in the Figure legends and the Results section, the supernatant from each culture medium was collected by centrifugation $(4,000 \mathrm{x} \mathrm{g})$ at $4^{\circ} \mathrm{C}$, and the prostaglandin E2 (PGE-2) released into the conditioned medium (100 $\mu \mathrm{l}$ of the cell supernatant) was quantified using an ELISA kit for PGE-2 (KGE004b; R\&D Systems, Minneapolis, MN, USA), strictly following the manufacturer's protocol. The OD of each well was determined within 30 min using a microplate reader (Thermo Labsystems, Santa Rosa, CA, USA) at $450 \mathrm{~nm}$.

Small interfering (si)RNA. The human CD147 siRNA and negative control siRNA were purchased from GenePharma (Shanghai, China). The siRNA sequence of CD147 was as follows: Sense 5'-GGUUCUUCGUGAGUUCCUCTT-3' and antisense 5'-GAGGAACUCACGAAGAACCTG-3'. The negative control (NC siRNA sequence was as follows: Sense 5'-UUC UCCGAACGUGUCACGUTT-3' and antisense 5'-ACGUGA CACGUUCGGAGAATT-3'. DharmaFECT-4 transfection reagent were purchased from Dharmacon, Inc. (Lafayette, CO, USA). The PANC-1 cells were seeded in 6-well plates at a density of $2.5 \times 10^{5}$ cells/well in MEM, and were grown for $16 \mathrm{~h}$ at $37^{\circ} \mathrm{C}$. Transfection was performed according to the manufacturer's instructions, using $4 \mu \mathrm{l}$ of DharmaFECT- 4 reagent and siRNA, at a final concentration of $100 \mathrm{nM} /$ well. The cells were cultured for a further $24 \mathrm{~h}$ at $37^{\circ} \mathrm{C}$, following which the total protein extracts (see the 'western blot analysis' section below) were isolated and analyzed using rabbit anti-human CD147 (cat. no. 13287; 1:1,000) and rabbit anti-human $\beta$-actin (cat. no. 4970; 1:1,000) antibodies (both obtained from Cell Signaling Technology, Danvers, MA, USA) for immunoblotting. The cells were collected, washed twice with pre-cooled phosphate-buffered saline (PBS), and invasion was measured.

Western blot analysis. The cells were lysed in SDS lysis buffer on ice for $30 \mathrm{~min}$. Cell debris was removed by centrifugation at $14,000 \mathrm{~g}$ at $4^{\circ} \mathrm{C}$ for $5 \mathrm{~min}$, and the protein contents of the cell lysates were determined using a Quick Start ${ }^{\mathrm{TM}}$ Bio-Rad Protein Assay kit (cat. no. CA5000201; Bio-Rad Laboratories, Inc.). The cell lysates with equal protein content (20 or $40 \mu \mathrm{g}$ ) were then loaded and separated by $12 \%$ SDS-PAGE (cat. no. PG113; Promoton, Nantong, Jiangsu, China). The protein bands were then electro-transferred onto a polyvinylidene fluoride membrane (Merck Millipore, Billerica, MA, USA) and blocked with $5 \%$ non-fat milk in Tris-buffered saline containing $0.1 \%$ Tween $20\left(\mathrm{pH} \mathrm{7.4)}\right.$ for $1 \mathrm{~h}$ at $37^{\circ} \mathrm{C}$. Subsequently, the membrane was incubated with the following antibodies, as appropriate: anti-c-Jun N-terminal kinase (JNK; cat. no. 9252; 1:1,000; rabbit anti-human), anti-phosphorylated (p-)JNK (cat. no. 9251; 1:1,000; rabbit anti-human), anti-extracellular signal-regulated kinase (ERK; cat. no. 9102; 1:1,000; rabbit anti-human), anti-p-ERK (cat. no. 9101; 1:1,000; rabbit anti-human), anti-p38 (cat. no. 9212; 1:1,000; rabbit anti-human), anti-p-p38 mitogen-activated protein kinases (MAPKs; cat. no. 9211; 1:1,000; rabbit anti-human; all antibodies from Cell Signaling Technology, Inc.) and anti-MMP-2 (cat. no. sc-13594; 1:500; mouse anti-human; Santa Cruz Biotechnology, Dallas, TX, USA) for at least $4 \mathrm{~h}$. After washing three times, the membranes were incubated for $1 \mathrm{~h}$ at room temperature with species-specific horseradish peroxidase (HRP)-conjugated secondary antibodies (goat anti-mouse antibody, cat. no. 115-035-003; or goat anti-mouse antibody, cat. no. 111-035-003; 1:2,000; Jackson ImmunoResearch Laboratories, Inc., West Grove, PA, USA). Immunoreactive bands were visualized using Immobilon Western chemiluminescent HRP substrate (Merck Millipore). As an internal control, the contents of $\beta$-actin in the samples were also immunoblotted using polyclonal anti-actin antibody as a primary antibody. The quantitative analysis of the proteins was performed by normalizing against $\beta$-actin by using Image Pro Plus 6.0 software (Media Cybernetics, Inc., Silver Spring, MD, USA).

Invasion assay. The invasive abilities of the pancreatic cancer cells were measured using a BD BioCoat ${ }^{\mathrm{TM}} \mathrm{BD}_{\text {Matrigel }^{\mathrm{TM}}}$ 


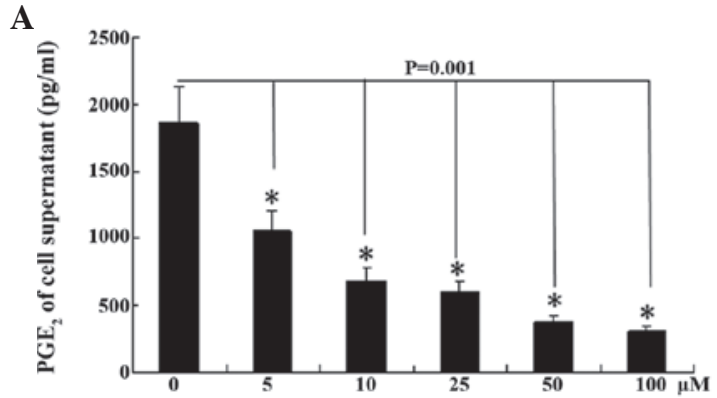

C

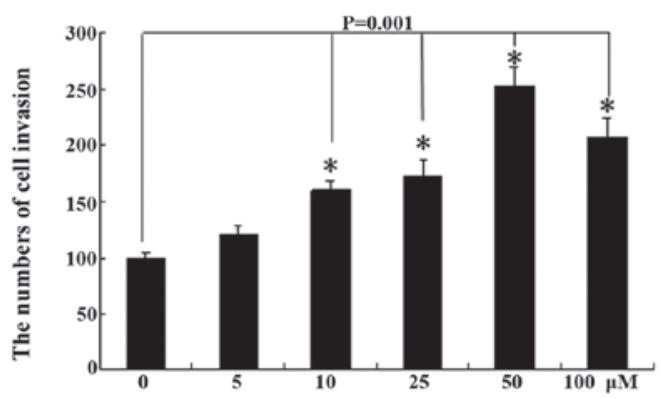

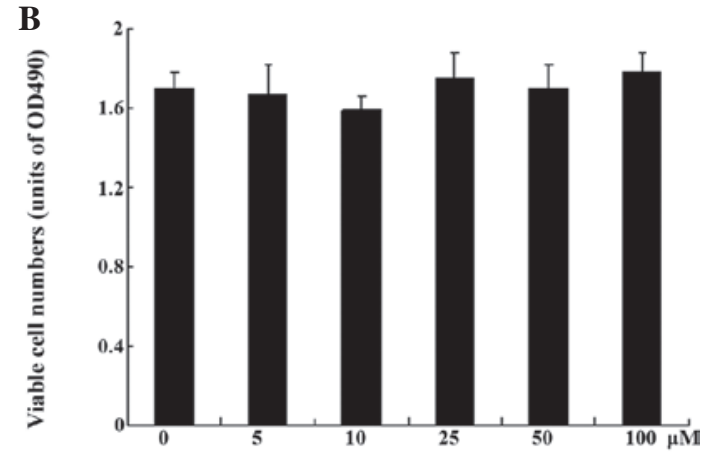

D

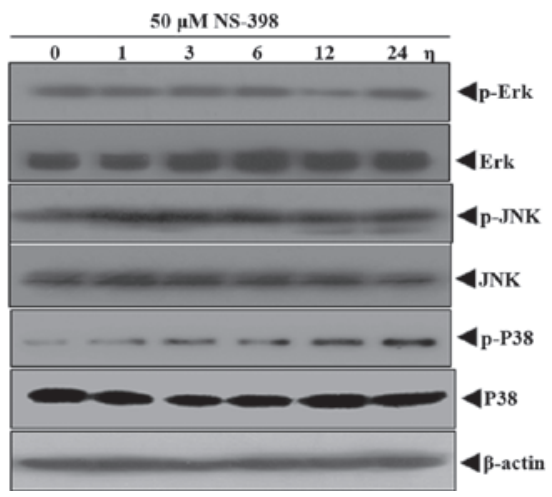

Figure 1. NS-398 enhances the invasiveness of pancreatic cancer cells and activates P38. The PANC-1 pancreatic cancer cells were treated with NS-398 (0, 5 , $10,25,50$ and $100 \mu \mathrm{M}$ ) for $24 \mathrm{~h}$. (A) Supernatant containing PANC-1 cells treated with NS-398 for $24 \mathrm{~h}$ was collected, following which the expression of PGE-2 was detected using an enzyme-linked immunosorbent assay. (B) Cell viability was detected using a Cell-Counting-Kit 8 assay. (C) PANC-1 cells were treated with NS-398 $(0,5,10,25,50$ and $100 \mu \mathrm{M})$ for $24 \mathrm{~h}$, following which the invasiveness of the PANC-1 cells was determined. The number of invasive cells was determined under an inverted microscope. (D) PANC-1 cells were treated with $50 \mu \mathrm{M} \mathrm{NS}-398$ for 0, 1, 3, 6, 12 and $24 \mathrm{~h}$. The expression levels of Erk, JNK, P38, P-Erk, P-JNK and P-P38 were analyzed using western blotting. Data are presented as the mean \pm standard deviation. PGE-2, prostaglandin E2; Erk, extracellular signal-regulated kinase; JNK, c-Jun-N-terminal kinase; P-, phosphorylated.

Invasion Chamber (BD Biosciences, Franklin Lakes, NJ, USA), according to the manufacturer's protocol. Briefly, the PANC-1 cells were treated with inhibitor or siRNA for $24 \mathrm{~h}$, as described above. The cells were then seeded onto the membrane of the upper chamber of the Transwell, at a concentration of $3-5 \times 10^{5} / \mathrm{ml}$ in $2 \mathrm{ml}$ DMEM. The medium in the upper chamber was serum-free, and the medium in the lower chamber contained $5 \%$ fetal calf serum as a source of chemoattractants. The number of cells that passed through the Matrigel-coated membrane were then counted on the undersides of the filters using a Nikon Eclipse Ti light microscope (Nikon Corporation, Tokyo, Japan).

Statistical analysis. Each sample was analyzed in triplicate, and experiments were repeated three times. All data are presented as the mean \pm standard deviation. All statistical analyses were performed using Microsoft Office Excel (Microsoft, Albuquerque, New Mexico, USA) and STASTISCA (StatSoft, Tulsa, OK, USA). Differences between mean values were evaluated using a paired $t$-test. $\mathrm{P}<0.05$ was considered to indicate a statistically significant difference.

\section{Results}

NS-398 enhances invasion and activates P38 signaling molecules in pancreatic cancer cells. The expression of PGE-2, a product of COX-2, is downregulated by NS-398 (17). In the present study, treatment of the PANC-1 cells with $5 \mu \mathrm{M}$ NS-398 significantly reduced the levels of PGE-2, and $50 \mu \mathrm{M}$ NS-398 decreased PGE-2 to the lowest levels observed. However, the CCK-8 kit, which was used to determine the effect of NS-398 on the proliferation of the PANC-1 pancreatic cancer cells, found that NS-398 had no significant inhibitory effect at either low or high concentrations (between 5 and $100 \mu \mathrm{M}$ ). To investigate why NS-398 was able to inhibit COX-2 activity, but did not lead to the inhibition of pancreatic cancer cell proliferation, $50 \mu \mathrm{M}$ NS-398 was used to treat the pancreatic cancer cells over a specific period of time, and the expression levels of MAPK signaling molecules were analyzed. The results showed that the p-P38 protein was significantly upregulated, however, the p-JNK and p-ERK signaling molecules were unaffected. The increase in p-P38 was observed in the pancreatic cancer cells treated with NS-398 for $1 \mathrm{~h}$, following which the levels of p-ERK gradually increased, peaked at $12 \mathrm{~h}$ and were maintained to $24 \mathrm{~h}$ (Fig. 1A-D).

SB-203580 restores the inhibitory effect of NS-398 on pancreatic cancer cell proliferation and inhibits the enhancement of invasion induced by NS-398. Pretreatment of the cells with SB-203580, a P38 signaling molecule inhibitor (18), was observed to inhibit NS-398-induced P38 activation. Accordingly, treatment with SB-203580 led to NS-398 inhib- 
A

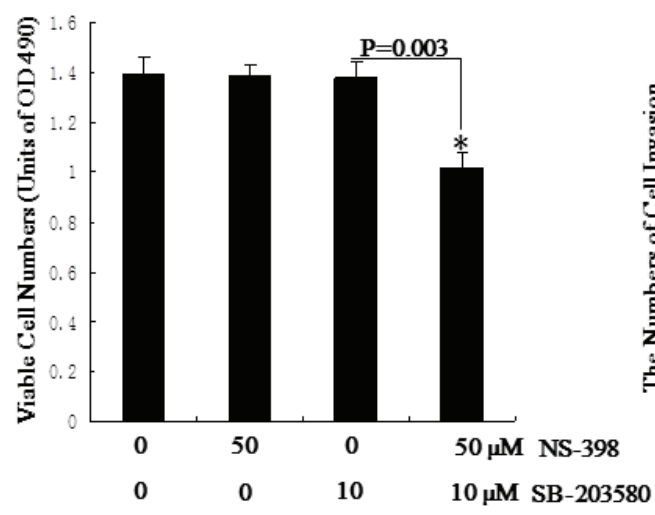

B

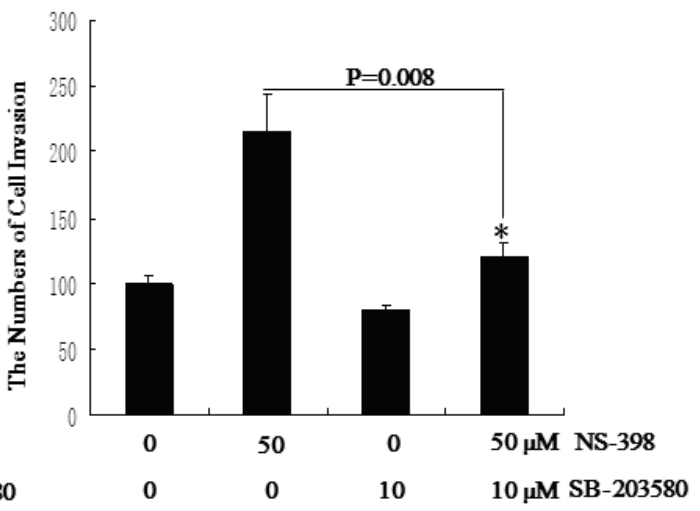

Figure 2. Treatment with the P38 inhibitor, SB-203580, restores inhibitory activity and inhibits invasion induced by NS-398. (A) PANC-1 cells were pretreated with $10 \mu \mathrm{M}$ SB-203580 for $2 \mathrm{~h}$, following which the cells were incubated with or without $50 \mu \mathrm{M}$ NS-398 for $24 \mathrm{~h}$. A Cell Counting Kit- 8 was used to detect cell proliferation. (B) Following SB-203580 pretreatment of the PANC-1 cells for $2 \mathrm{~h}$, the pancreatic cancer cells were incubated with or without NS-398 for $24 \mathrm{~h}$. Invasiveness of the PANC-1 cells was determined using an inverted microscope. Data are presented as the mean \pm standard deviation. OD, optical density.

A

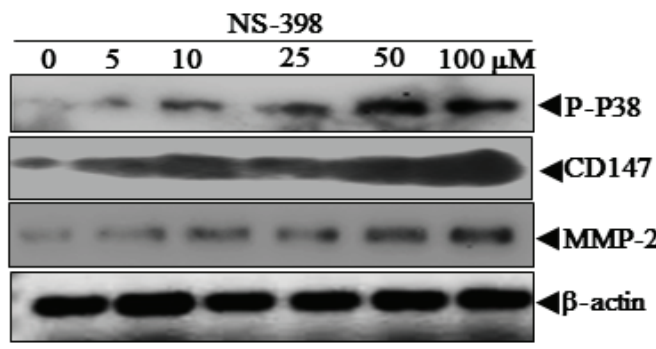

B

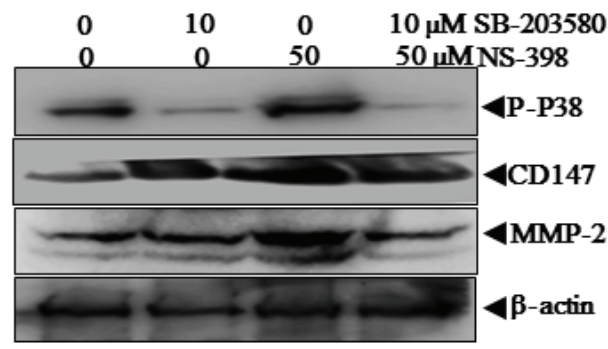

C

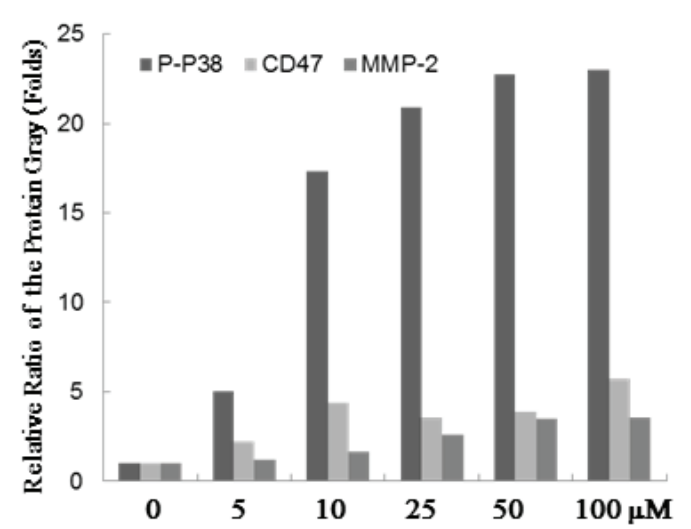

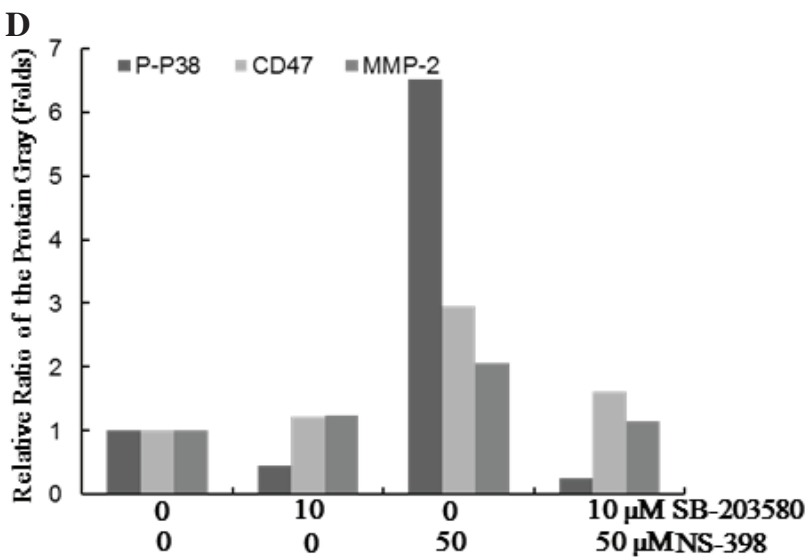

Figure 3. NS-398 induces the expression of CD147 and MMP-2 via the activation of P38 in pancreatic cancer cells. (A) PANC-1 cells were treated with 0, 5 , 10, 25, 50 and $100 \mu \mathrm{M}$ NS-398 for $24 \mathrm{~h}$. The expression levels of P-P38, CD147 and MMP-2 were analyzed using western blotting. (B) PANC-1 cells were pretreated with $20 \mu \mathrm{M} \mathrm{SB}-203580$ for $2 \mathrm{~h}$, following which the cells were incubated with or without $50 \mu \mathrm{M} \mathrm{NS}-398$ for $24 \mathrm{~h}$. Western blot analysis was used to detect the expression levels of P-P38, CD147 and MMP-2. (C and D) The densitometric analysis for the data shown in (A) and (B) for P-P38, CD147 and MMP-2 is shown. P-, phosphorylated; CD147, cluster of differentiation 147; MMP-2, matrix metalloproteinase-2.

iting the proliferation activity of the pancreatic cancer cells. Invasive in vitro experiments were also performed, which demonstrated that treatment with $50 \mu \mathrm{M}$ NS-398 increased the invasiveness of the pancreatic cancer cells, whereas the P38 inhibitor, SB-203580, significantly reduced pancreatic cancer cell invasion, compared with the NS-398-treated cells. SB-203580 was observed to completely inhibit the NS-398-induced increase in pancreatic cancer cell invasiveness (Fig. 2A and B).
NS-398 induces the expression levels of CD147 and MMP-2 through the activation of $P 38$ in pancreatic cancer cells. The activation of the P38 signaling pathway is closely associated with the activation of the CD147-MMP-2 signaling pathway (19). In order to determine the role of P38 signaling molecules in the induction of CD147 and downstream MMP-2 by NS-398, the PANC-1 cells were treated with $50 \mu \mathrm{M}$ NS-398 for the indicated durations. The results revealed that the levels of CD147 and MMP-2 were upregulated following 
A

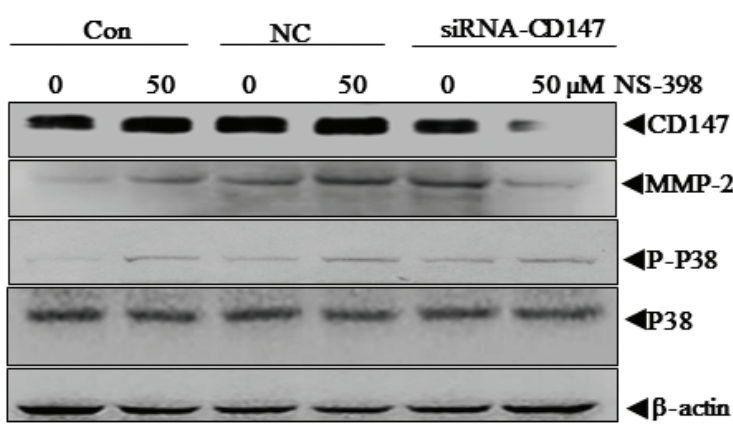

C

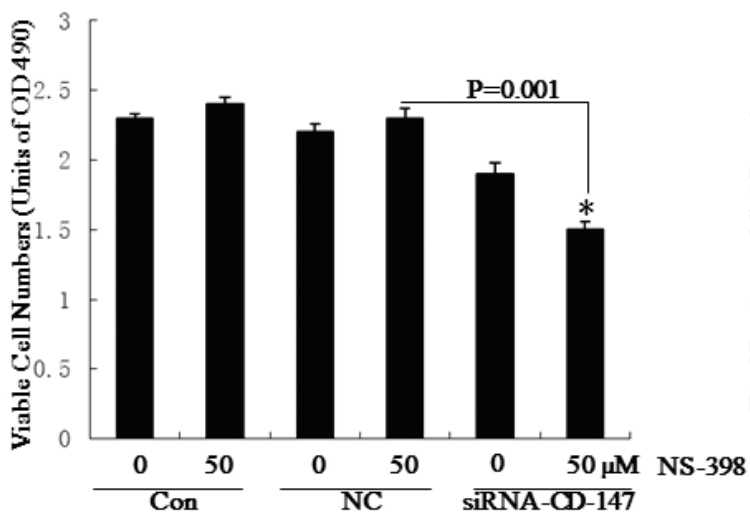

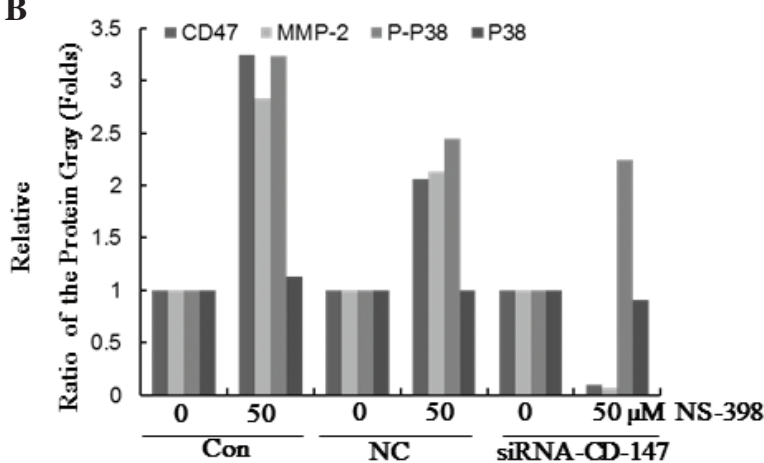

D

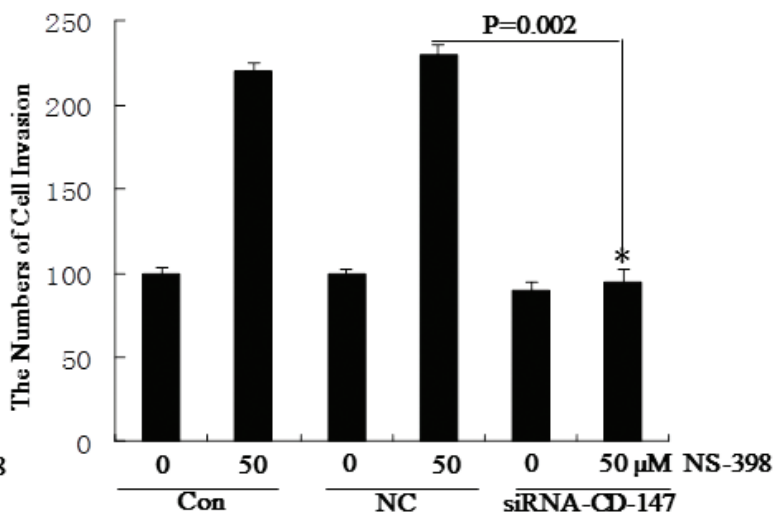

Figure 4. CD147 siRNA inhibits the expression of MMP-2 induced by NS-398. siRNAs targeted specifically against CD147 or negative control siRNA (NC) were transiently transfected into PANC-1 cells. At $24 \mathrm{~h}$ post-transfection, the cells were incubated with or without $50 \mu \mathrm{M} \mathrm{NS}-398$ for $24 \mathrm{~h}$. (A) Expression levels of CD147, MMP-2, P-P38 and P38 were detected using western blotting, with $\beta$-actin as a loading control. (B) The densitometric analysis of the western blot in (A) for P-P38, CD147 and MMP-2 is shown. (C) Cell viability was evaluated using a Cell Counting Kit-8 assay. (D) Invasiveness of PANC-1 was determined using an inverted microscope, under which number of invasive cells were counted. Data are presented as the mean \pm standard deviation. CD147, cluster of differentiation 147; siRNA, small interfering RNA; Con, control; NC, negative control; OD, optical density.

activation of the P38 signaling molecules. SB-203580 inhibited NS-398-induced P38 activation, and also inhibited the expression levels of CD147 and downstream MMP-2 (Fig. 3A and $\mathrm{B})$.

CD147 siRNA inhibits the NS-398-induced invasion of pancreatic cancer cells and restores anti-proliferation activity. To further confirm the hypothesis that NS-398 mediates the CD147-MMP-2 signaling pathway, involved in pancreatic cancer cell invasiveness, through the activation of P38 signaling molecules, CD147 siRNAs were transfected into PANC-1 cells for $24 \mathrm{~h}$. The cells were then treated with or without $50 \mu \mathrm{M} \mathrm{NS}-398$, and western blot analysis of the protein expression levels was performed. The results indicated that the NS-398-induced expression of MMP-2 was inhibited by the CD147 siRNAs, however, the activation induced by NS-398 remained. Invasive in vitro experiments were also performed, which revealed that the CD147 siRNAs significantly inhibited the NS-398-induced increase in pancreatic cancer cell invasiveness. CD147 siRNA treatment also restored the anti-proliferative effect of NS-398 in the pancreatic cancer cells (Fig. 4A-C).

\section{Discussion}

Previous studies have shown that COX-2 is overexpressed or activated in pancreatic cancer cells (20-23). In the present study, the effects of the COX-2 inhibitor, NS-398, on cell viability, invasion and invasion-associated cellular properties were determined. The resulting data indicated that NS-398 did not inhibit proliferation, but it promoted pancreatic cancer cell invasiveness. Furthermore, the results revealed that treatment with NS-398 led to the activation of P38-mediated proliferation and invasiveness of the pancreatic cancer cells.

In the present study, following incubation of the pancreatic cancer cells with NS-398, the levels of PGE-2 in the culture supernatant were reduced in a NS-398 dose-dependent manner. These data are consistent with previous relevant reports on the effects of NS-398 on COX-2 (15-24). Notably, treatment with NS-398 had no significant effect on pancreatic cancer cell proliferation or viability. NS-398 can induce growth inhibition, and even apoptosis of tumor cells, including gastric cancer and colorectal cancer $(25,26)$. The results of the present study suggested that NS-398 activated a signaling molecule, which antagonized the inhibitory effects of NS-398 on the COX-2 signaling pathway, which led to growth inhibition. Previous studies have found that the ERK signaling pathway can be activated by NS-398 (27). A similar result was observed in the present study, in which NS-398 activated P38, however, the other MAPK signaling pathways, ERK and JNK, were not significantly affected. SB-203580, an inhibitor of P38 activation, restored the inhibitory effect of NS-398 on pancreatic cancer cell growth. This indicated that the activation of P38 was involved in the antagonism of NS-398-induced prolifera- 
tion inhibition, and increased the invasion of pancreatic cancer cells.

Abnormal activation of the P38 signaling pathway may trigger the tumor cell CD147 signaling pathway, and CD147, a member of the immunoglobulin superfamily, has been identified as a receptor for CyPA $(28,29)$. However, whether NS-398 can induce CD147 signaling molecules in pancreatic cancer cells remains to be elucidated. In the present study, treatment of the pancreatic cancer cells with NS-398 at different concentrations for $24 \mathrm{~h}$ led to upregulation in the levels of CD147 in dose-dependent manner. NS-398 can activate the P38 signaling pathway, and it has been reported that the P38 signaling pathway can increase the expression levels of MMP-2 and CD147 (30-34). The present study hypothesized that NS-398 upregulates the expression of CD147-MMP-2 through the activation of P38 by NS-398. This hypothesis was confirmed following treatment of pancreatic cells with SB-203580, an ERK inhibitor, which inhibited P38 activation by NS-398, following which the upregulation of MMP-2 and CD147 were inhibited in the NS-398-treated pancreatic cancer cells.

CD147-MMP-2 signaling is associated with tumor cell invasiveness, and MMP-2 is a downstream molecule of CD147 that is involved in cell migration and invasiveness $(34,35)$. Notably, NS-398 was observed to increase the invasiveness of pancreatic cancer cells, whereas the P38 inhibitor, SB-203580, inhibited the invasive abilities of pancreatic cancer cells induced by NS-398, indicating that the NS-398-induced increase in pancreatic cancer cell invasiveness was associated with the activation of P38.

The CD147 downstream molecule, MMP-2, is an important invasive factor (36). The present study found that NS-398 activated the expression of MMP-2. SB-203580 and CD147 siRNA inhibited the NS-398-induced increase in pancreatic cancer cell invasion, whereas the NS-398-induced expression of MMP-2 was restored by CD147-siRNA and SB-203580. However, P38 remained activated in the CD147 siRNA and NS-398 co-treated pancreatic cancer cells. According to these data, the present study hypothesized that NS-398 enhanced pancreatic cancer cell invasiveness by the P38-CD147-MMP-2 signaling pathway, and the mechanisms by which NS-398 activates P38 and CD147-MMP-2 warrant further investigation.

In conclusion, the results of the present study suggested that NS-398 inhibited COX-2 activity in the pancreatic cancer cells, however, it did not inhibit pancreatic cancer cell proliferation or vitality. By contrast, NS-398 activated the P38 signaling pathway in the pancreatic cancer cells, which was involved in pancreatic cancer cell proliferation resistance and activated CD147-MMP-2, increasing pancreatic cancer cells invasiveness. These results demonstrated that treatment with NS-398 alone is insufficient in treating patients with pancreatic cancer, and the application of NS-398 in the treatment of pancreatic cancer patients may pose a potential risk.

\section{Acknowledgements}

This study was supported in part by the National Natural Science Foundation of China (no. 81172322), the Shanghai Municipal Education Committee (no. 13ZZ089), the Science and Technology Committee of Shanghai (no. 14401901500) and the Science and Technology Committee of Baoshan District (no. 12-E-2).

\section{References}

1. Nentwich MF, Bockhorn M, König A, Izbicki JR and Cataldegirmen G: Surgery for advanced and metastatic pancreatic cancer-current state and trends. Anticancer Res 32: 1999-2002, 2012.

2. Fidler IJ: Origin and biology of cancer metastasis. Cytometry 10: 673-680, 1989.

3. Liotta LA, Steeg PS and Stetler-Stevenson WG: Cancer metastasis and angiogenesis: An imbalance of positive and negative regulation. Cell 64: 327-336, 1991.

4. Hanahan D and Weinberg RA: Hallmarks of cancer: The next generation. Cell 144: 646-674, 2011.

5. Walsh N, O'Donovan N, Kennedy S, Henry M, Meleady P, Clynes M and Dowling P: Identification of pancreatic cancer invasion-related proteins by proteomic analysis. Proteome Sci 7: 3, 2009.

6. Ramer R, Weinzierl U, Schwind B, Brune K and Hinz B: Ceramide is involved in $\mathrm{r}(+)$-methanandamide-induced cyclooxygenase-2 expression in human neuroglioma cells. Mol Pharmacol 64: 1189-1198, 2003.

7. Mollace V, Muscoli C, Masini E, Cuzzocrea S and Salvemini D: Modulation of prostaglandin biosynthesis by nitric oxide and nitric oxide donors. Pharmacol Rev 57: 217-252, 2005.

8. Pereira C, Sousa H, Silva J, Brandão C, Elgueta-Karstegl C, Farrell PJ, Medeiros R and Dinis-Ribeiro M: The -1195G allele increases the transcriptional activity of cyclooxygenase- 2 gene (COX-2) in colon cancer cell lines. Mol Carcinog 53 (Suppl 1): E92-E95, 2014.

9. Wójcik M, Ramadori P, Blaschke M, Sultan S, Khan S, Malik IA, Naz N, Martius G, Ramadori G and Schultze FC: Immunodetection of cyclooxygenase-2 (COX-2) is restricted to tissue macrophages in normal rat liver and to recruited mononuclear phagocytes in liver injury and cholangiocarcinoma. Histochem Cell Biol 137: 217-233, 2012.

10. Young AL, Chalmers CR, Hawcroft G, Perry SL, Treanor D, Toogood GJ, Toogood GJ, Jones PF and Hull MA: Regional differences in prostaglandin $\mathrm{E}_{2}$ metabolism in human colorectal cancer liver metastases. BMC Cancer 13: 92, 2013.

11. Shibata-Kobayashi S, Yamashita H, Okuma K, Shiraishi K, Igaki $\mathrm{H}$, Ohtomo $\mathrm{K}$ and Nakagawa K: Correlation among 16 biological factors [p53, p21(waf1), MIB-1 (Ki-67), p16 (INK4A), cyclin D1, E-cadherin, Bcl-2, TNF- $\alpha$, NF- $\kappa$ B, TGF- $\beta$, MMP-7, COX-2, EGFR, HER2/neu, ER and HIF-1 $\alpha$ ] and clinical outcomes following curative chemoradiation therapy in 10 patients with esophageal squamous cell carcinoma. Oncol Lett 5: 903-910, 2013.

12. Yan WF, Sun PC, Nie CF and Wu G: Cyclooxygenase-2 polymorphisms were associated with the risk of gastric cancer: Evidence from a meta-analysis based on case-control studies. Tumour Biol 34: 3323-3330, 2013.

13. Hillion J, Smail SS, Di Cello F, Belton A, Shah SN, Huso T, Schuldenfrei A, Nelson DM, Cope L, Campbell N, et al: The HMGA1-COX-2 axis: A key molecular pathway and potential target in pancreatic adenocarcinoma. Pancreatology 12: 372-379, 2012.

14. Okami J, Nakamori S, Hiraoka N, Tsujie M, Hayashi N, Yamamoto H, Fujiwara Y, Nagano H, Dono K, Umeshita K, et al: Suppression of pancreatic cancer cell invasion by a cyclooxygenase-2-specific inhibitor. Clin Exp Metastasis 20: 577-584, 2003.

15. Duan DP, Dang XQ, Wang KZ, Wang YP, Zhang H and You WL: The cyclooxygenase-2 inhibitor NS-398 inhibits proliferation and induces apoptosis in human osteosarcoma cells via downregulation of the survivin pathway. Oncol Rep 28: 1693-1700, 2012.

16. Youns M, Efferth T and Hoheisel JD: Transcript profiling identifies novel key players mediating the growth inhibitory effect of NS-398 on human pancreatic cancer cells. Eur J Pharmacol 650: 170-177, 2011.

17. Araki E, Forster C, Dubinsky JM, Ross ME and Iadecola C: Cyclooxygenase-2 inhibitor ns-398 protects neuronal cultures from lipopolysaccharide-induced neurotoxicity. Stroke 32: 2370-2375, 2001

18. Kumar S, Boehm J and Lee JC: p38 MAP kinases: Key signalling molecules as therapeutic targets for inflammatory diseases. Nat Rev Drug Discov 2: 717-726, 2003. 
19. Chen X, Lin J, Kanekura T, Su J, Lin W, Xie H, Wu Y, Li J, Chen $\mathrm{M}$ and Chang J: A small interfering CD147-targeting RNA inhibited the proliferation, invasiveness and metastatic activity of malignant melanoma. Cancer Res 66: 11323-11330, 2006

20. Yoshida S, Ujiki M, Ding XZ, Pelham C, Talamonti MS, Bell RH Jr, Denham W and Adrian TE: Pancreatic stellate cells (PSCs) express cyclooxygenase-2 (COX-2) and pancreatic cancer stimulates COX-2 in PSCs. Mol Cancer 4: 27, 2005.

21. Yip-Schneider MT, Barnard DS, Billings SD, Cheng L, Heilman DK, Lin A, Marshall SJ, Crowell PL, Marshall MS and Sweeney CJ: Cyclooxygenase-2 expression in human pancreatic adenocarcinomas. Carcinogenesis 21: 139-146, 2000.

22. Molina MA, Sitja-Arnau M, Lemoine MG, Frazier ML and Sinicrope FA: Increased cyclooxygenase-2 expression in human pancreatic carcinomas and cell lines: Growth inhibition by nonsteroidal anti-inflammatory drugs. Cancer Res 59: 4356-4362, 1999.

23. Tucker ON, Dannenberg AJ, Yang EK, Zhang F, Teng L, Daly JM, Soslow RA, Masferrer JL, Woerner BM, Koki AT and Fahey TJ III: Cyclooxygenase-2 expression is up-regulated in human pancreatic cancer. Cancer Res 59: 987-990, 1999.

24. Wang X, Liang Y, Wang J and Wang M: Effect of NS-398, a cyclooxygenase-2 selective inhibitor, on the cytotoxicity of cytotoxic T lymphocytes to ovarian carcinoma cells. Tumour Biol 34: 1517-1522, 2013

25. Honjo S, Osaki M, Ardyanto TD, Hiramatsu T, Maeta N and Ito H: COX-2 inhibitor, NS398, enhances Fas-mediated apoptosis via modulation of the PTEN-Akt pathway in human gastric carcinoma cell lines. DNA Cell Biol 24: 141-147, 2005.

26. Banu N, Buda A, Chell S, Elder D, Moorghen M, Paraskeva C, Qualtrough D and Pignatelli M: Inhibition of COX-2 with NS-398 decreases colon cancer cell motility through blocking epidermal growth factor receptor transactivation: Possibilities for combination therapy. Cell Prolif 40: 768-779, 2007.

27. Elder DJ, Halton DE, Playle LC and Paraskeva C: The MEK/ERK pathway mediates COX-2-selective NSAID-induced apoptosis and induced COX-2 protein expression in colorectal carcinoma cells. Int J Cancer 99: 323-327, 2002.
28. Yurchenko V, Constant S and Bukrinsky M: Dealing with the family: CD147 interactions with cyclophilins. Immunology 117: 301-309, 2006

29. Yurchenko V, Constant S, Eisenmesser E and Bukrinsky M: Cyclophilin-CD147 interactions: A new target for anti-inflammatory therapeutics. Clin Exp Immunol 160: 305-317, 2010.

30. Gabison EE, Hoang-Xuan T, Mauviel A and Menashi S: EMMPRIN/CD147, an MMP modulator in cancer, development and tissue repair. Biochimie 87: 361-368, 2005.

31. Yang Y, Lu N, Zhou J, Chen ZN and Zhu P: Cyclophilin A up-regulates MMP-9 expression and adhesion of monocytes/macrophages via CD147 signalling pathway in rheumatoid arthritis. Rheumatology (Oxford) 47: 1299-1310, 2008.

32. Tang Y, Nakada MT, Rafferty P, Laraio J, McCabe FL, Millar H, Cunningham M, Snyder LA, Bugelski P and Yan L: Regulation of vascular endothelial growth factor expression by EMMPRIN via the PI3K-Akt signaling pathway. Mol Cancer Res 4: 371-377, 2006.

33. Nabeshima K, Iwasaki H, Koga K, Hojo H, Suzumiya J and Kikuchi M: Emmprin (basigin/CD147): Matrix metalloproteinase modulator and multifunctional cell recognition molecule that plays a critical role in cancer progression. Pathol Int 56: 359-367, 2006.

34. Sun J and Hemler ME: Regulation of MMP-1 and MMP-2 production through CD147/extracellular matrix metalloproteinase inducer interactions. Cancer Res 61: 2276-2281, 2001.

35. Kanekura T, Chen X and Kanzaki T: Basigin (CD147) is expressed on melanoma cells and induces tumor cell invasion by stimulating production of matrix metalloproteinases by fibroblasts. Int J Cancer 99: 520-528, 2002.

36. Kolli-Bouhafs K, Boukhari A, Abusnina A, Velot E, Gies JP, Lugnier $\mathrm{C}$ and Rondé $\mathrm{P}$ : Thymoquinone reduces migration and invasion of human glioblastoma cells associated with FAK, MMP-2 and MMP-9 down-regulation. Invest New Drugs 30: 2121-2131, 2012. 